The Theory of Planned Behavior as a Model of Academic Dishonesty in Engineering and Humanities Undergraduates

\author{
Trevor S. Harding ${ }^{1}$, Matthew J. Mayhew ${ }^{2}$, Cynthia J. Finelli ${ }^{3}$, Donald D. Carpenter ${ }^{4}$. \\ 1 California Polytechnic State University \\ 2 New York University \\ 3 University of Michigan \\ 4 Lawrence Technological University
}

Trevor S. Harding, Materials Engineering Department, California Polytechnic State University We would like to thank Diane Waryold, Elizabeth Kiss, Tim Dodd, the Center for Academic Integrity, the John Templeton Foundation, and the Kern Family Foundation for their support of this research. The opinions expressed in this article do not necessarily reflect the views of the Center for Academic Integrity or the John Templeton Foundation. 


\title{
The Theory of Planned Behavior as a Model of Academic Dishonesty in Engineering and Humanities Undergraduates
}

\begin{abstract}
This study examines the use of a modified form of the Theory of Planned Behavior in understanding the decisions of undergraduate students in engineering and humanities to engage in cheating. We surveyed 527 randomly selected students from three academic institutions. Results supported the use of the model in predicting ethical decision-making regarding cheating. In particular, the model demonstrated how certain variables (gender, discipline, high school cheating, education level, international student status, participation in Greek organizations or other clubs) and moral constructs related to intention to cheat, attitudes toward cheating, perceptions of norms with respect to cheating, and ultimately, cheating behaviors. Further the relative importance of the Theory of Planned Behavior constructs was consistent regardless of context, whereas the contributions of variables included in the study that were outside the theory varied by context. Of particular note were findings suggesting that the extent of cheating in high school was a strong predictor of cheating in college and that engineering students reported cheating more frequently than students in the humanities, even when controlling for the number of opportunities to do so.
\end{abstract}

Key words: academic dishonesty, cheating, Theory of Planned Behavior, engineering, humanities

In today's society where technology pervades every aspect of our lives, the ethical behavior of engineers and scientists is more important than ever. This need to graduate engineers who are more conscious of their ethical and professional responsibilities is supported by The Engineer of 2020 report produced by the National Academy of Engineering (NAE) that concluded future engineers would need to "possess a working framework upon which high ethical standards and a strong sense of professionalism can be developed” (National Academy of Engineering, 2004, p.56). Another NAE report, Emerging Technologies and Ethical Issues in Engineering, concluded that, given current curricula and educational practices, future engineers will be trained to advance technologies, but will not be trained to address the "social and ethical implications" of these technologies (National Academy of Engineering, 2003, p.v).

This new emphasis on ethics implies the need for innovative approaches to improving the ethical development of current engineering and science students. However, current modes of delivery (e.g. engineering ethics courses, philosophical ethics courses, embedded ethics modules, engineering ethics case studies, etc.) vary widely, and research addressing the extent to which they promote ethical reasoning yields inconclusive results (Bebeau, 2002; Bebeau \& Thoma, 1999; Etter et al, 2004); some modes of delivery were successful in promoting moral reasoning, others were not. Further, based on high rates of cheating among engineering undergraduates (McCabe, 1997; Harding et al, 2006a; Carpenter et al, 2006), it would seem that these modes of delivery are having little effect on behavior. As such, current approaches to teaching engineering ethics have been inadequate in addressing the ethical development of engineering undergraduates. In order to develop more robust interventions that can significantly improve engineering students' ethical development, educators need a theoretical framework for understanding the underlying psychological mechanisms involved in students' ethical decisionmaking and behavior. It is our hope that the development of such a framework will help 
educators create interventions effective in promoting ethical decision-making and behavior among undergraduate engineering students.

The purpose of this study is to explore the use of a modified version of the Theory of Planned Behavior (Ajzen, 2002) as a model predicting engineering and humanities undergraduate students' engagement in unethical behaviors, specifically cheating on tests and homework. We use cheating as a proxy for unethical behavior among undergraduates for three reasons. First, given the high rates of self-reported cheating among engineering undergraduates already measured (Carpenter et al., 2006; McCabe, 1997), cheating represents a behavior that is familiar to most, if not all, undergraduates. Second, the decision of whether or not to cheat is an ethical one that requires students to consider a behavior (i.e. cheating) they know to be in violation of established policies, codes, and perhaps norms. Third, cheating in college among engineering students has been correlated with unethical behaviors in engineering professional practice (Harding, Finelli \& Carpenter, 2006b; Carpenter, Harding \& Finelli, 2006; Harding et al., 2004a; Harding et al., 2004b; Harding et al., 2003a; Harding, et al., 2003b). For these reasons, selfreported cheating behavior serves as the outcome for this study; however, in order to more fully understand how students approach their decisions to cheat, we must also understand how this behavior varies by type of context, namely homework and test cheating.

Do students approach cheating on tests and homework in the same way? How do the underlying psychological mechanisms that predict cheating behaviors differ for students in a testing versus homework context? Previous research has established that type of cheating plays a significant role in determining both the frequency of cheating and students' attitudes toward it (Passow et al, 2006). Findings from this study showed that educational level, frequent past cheating in high school, and situational factors were important predictors of cheating on tests but not on homework assignments. Thus, in this study we separated analyses for models predicting testing and homework cheating, respectively. Although some variability exists in how students approach cheating based on the context in which the behavior takes place, it does not preclude adopting a common approach to understanding the psychological mechanisms students use in making decisions to cheat. For this reason, we use the same variables to construct our predictive models, but pay careful attention to the relative contribution each makes to predicting the test and homework cheating, respectively.

Two of these variables, moral obligation and moral reasoning, were added to the constructs in the original Theory of Planned Behavior model developed by Ajzen (1991). We added these variables to enhance the predictive capabilities of the theory in the context of cheating. Ajzen (1991) describes moral obligation as "personal feelings of ... responsibility to perform, or refuse to perform, a certain behavior” (p.289). Alternatively, moral reasoning is "a psychological construct that characterizes the process by which people determine that one course of action in a particular situation is morally right and another course of action is wrong” (Rest, Thoma, \& Edwards, 1997, p. 5). Inclusion of these additional moral components in the current study is important for several reasons. First, the decision to cheat is an ethical one, and a moral component may be critical in such decisions. Second, it has been shown that college has a particularly influential effect on gains in moral reasoning scores (Rest \& Narvaez, 1994; King \& Mayhew, 2002), such that there may be significant differences in this component according to college level. Third, opportunities to participate in discussions of differing moral perspectives are not often provided in an undergraduate engineering program, so there may be differences in the relative influence of a moral component by discipline. For these reasons, we situated these moral constructs within our understanding of and subsequent operational model for the Theory of 
Planned Behavior in an effort to create the most robust framework for understanding the psychological mechanisms contributing to students' decisions to cheat.

Finally, the modified form of the Theory of Planned Behavior included a series of demographic variables that have been found to exert significant influence on outcomes related to cheating. Specifically, we investigated the effects of selected pre-college (e.g., high school cheating behavior), demographic (e.g. gender), and collegiate (e.g. discipline and education level) variables on constructs identified in the Theory of Planned Behavior in an effort to predict cheating behaviors on exams and homework among engineering and humanities students. For a complete review of the influence of these variables on cheating see Whitley and Keith-Spiegel (2002) and Passow, et al (2006).

\section{THEORY OF PLANNED BEHAVIOR}

We rely on a modified form of Ajzen's Theory of Planned Behavior, shown in Figure 1, as a model of the decision-making process used by students when forming the cheating intention and its subsequent behavior (Ajzen, 1991; Ajzen, 2002). Three assumptions guided our decision to use and modify the Theory of Planned Behavior as our theoretical framework for understanding student cheating. First, we assume that cheating is the result of rational choice under the volitional control of the individual. Second, we consequently assume that such behavior is predictable and can be understood through statistical modeling. Third, Ajzen's Theory of Planned Behavior has earlier been shown to explain considerable amounts of variance in measures of student cheating and other unethical behaviors (Beck \& Ajzen, 1991).

$* * * * * * * * * * * * * * * * *$ Insert Figure 1 Here $* * * * * * * * * * * * * * * * * *$

The premise of the Theory of Planned Behavior is that individuals make rational decisions to engage in specific behaviors based on their own beliefs about the behaviors and their expectation of a positive outcome after having engaged in the behaviors. According to Ajzen (2002), an intention to perform a behavior is determined by three components: attitude toward a behavior, subjective norm, and perceived behavioral control. Ajzen defines intention as “...indications of how hard people are willing to try, of how much of an effort they are planning to exert, in order to perform the behavior" (p. 113). He defines attitude toward a behavior as "a disposition to respond favorably or unfavorably to an object, person, institution, or event.” (p.4). Subjective norm can be considered the individual's perception that other individuals important to the respondent believe the respondent should perform the behavior of interest. Finally, perceived behavioral control is the "perceived ease of performing the behavior based on past experience and anticipated impediments” (p.132). In the aggregate, these components directly influence an individual's intention to complete a behavior, and intention in turn influences whether an individual ultimately engages in the behavior. To the extent that the individual's perception of behavioral control is in agreement with actual behavioral control, Ajzen (1991) postulated that perceived behavioral control serves as a proxy for actual behavioral control, therefore having a direct influence on both intention and the actual behavior.

Support for the Theory of Planned Behavior as a predictive model of cheating comes from Whitley (Whitley, 1998; Whitley \& Kieth-Spiegel, 2002) who conducted a meta-analysis of 107 studies of academic dishonesty. Among other findings, Whitley reported that: (1) students with favorable attitudes of cheating are more likely to cheat than students with unfavorable attitudes (attitude toward behavior); (2) students who perceive that social norms permit cheating do so to a 
greater extent than other students (subjective norm); and (3) students who perceive themselves as more effective cheaters are more likely to cheat (perceived behavioral control). Further support for the theory as a predictive model for cheating comes from Beck and Ajzen (1991) who showed that the model successfully predicted most of the systematic variance in student decisions to cheat.

Despite substantial support for the Theory of Planned Behavior as a means of predicting behavior, research continues to examine additional variables that might enhance the predictive capabilities of the theory in certain circumstances. For example, Armitage and Conner (1999) showed that correlations between moral norms and other constructs of the theory were large, and they argued that moral norms might play an important role in the theory. Our own work showed that moral obligation, as well as feelings of shame, was an important deterrent to cheating regardless of context (Passow, et al., 2006). Finally, Beck and Ajzen (1991) found that moral obligation was a significant predictor of both cheating behavior and the formation of the intent to cheat. Further, they found that moral obligation provided modest gains in the predictive power of the Theory of Planned Behavior. For these reasons, we refined the TPB to include two additional moral components (moral obligation and moral reasoning), a measure of past cheating behavior, and other selected demographic variables. The purpose of this study, therefore, is to examine the unethical behavior of engineering and humanities students within the context of cheating using the modified Theory of Planned Behavior as a framework. What we hope is that this modified version of the theory will serve as an empirical roadmap for educators interested in developing interventions designed to reduce and ideally stop students from cheating on homework and exams.

\section{Study Design}

\section{METHODOLOGY}

The study employs a cross-sectional design (Figure 2) to examine test and homework cheating among undergraduate students from two disciplines (engineering and humanities) and two college levels (first-year students and seniors). We based our sampling decisions on evidence suggesting that engineering students self-report significantly higher rates of cheating than do students in most other disciplines (Bowers, 1964; Harp \& Taietz, 1966; McCabe, 1997) and that humanities students historically report lower levels of cheating than all other disciplines (Bowers, 1964; Harp \& Taietz, 1966; McCabe, 1997). By examining these two populations of students, we anticipate a greater difference in the relative contributions of the Theory of Planned Behavior constructs making any differences that do exist easier to measure. In addition, we selected first-year students and seniors based on evidence demonstrating that exposure to and engagement in college has a dramatic effect on students' moral development (Pascarella \& Terenzini, 1991; King and Mayhew, 2002, 2004) and that the extent to which students are exposed to the values and ideals of other individuals and cultures in college is critical to helping them construct moral identities (Rogers, 2002). The recruitment of only freshmen and seniors was an intentional effort to survey students at the very beginning and end of a baccalaureate experience to assess the effect of a traditional 4 year program on the study outcome variables.

***************Insert Figure 2 Here

\section{Sample Descriptives}

A total of 527 undergraduate respondents from three institutions participated in this study. Of this number, 42\% attended a large Doctoral Research Extensive public institution (School A), $40 \%$ attended a small private Baccalaureate Specialty institution (School B), and 18\% attended a 
mid-sized private Masters I institution (School C). Engineering students made up 78.8\% of the sample, with humanities students accounting for the remainder. Humanities students were defined as being enrolled in a degree granting program within a college of liberal arts and sciences, but outside the social and physical sciences (e.g. philosophy, art, history, languages, music, etc.). Engineering students were defined as being enrolled in an accredited engineering degree granting program. Unlike the engineering students, humanities students were recruited from school A only - schools B and C did not have programs in the humanities from which to recruit students.

The sample consisted of 32.5\% females. However, among the engineering students in the sample, women constituted only 21.2\% - a number similar to the 2004 national average for female enrollment in bachelor's engineering programs (Gibbons, 2005a). Among the humanities students, $73.5 \%$ were female. The average age of respondents was 20.0 years $(\sigma=2.81)$. Slightly more than half $(60.2 \%)$ of the sample consisted of freshmen students. The numbers of freshmen in each of the two disciplines were comparable.

Caucasians made up the largest portion of the sample (84.4\%) with 9.9\% identifying themselves as Asian/Pacific Islander, 5.3\% African American/Black, 4.0\% Hispanic/Latino, and 1.6\% Native American/American Indian. International students accounted for $6.3 \%$ of the sample; however, the majority of these students was enrolled in engineering programs (93.5\%) and was ethnically Asian/Pacific Islander (58\%). Within engineering, international students represented $7.5 \%$ of the sample, a number similar to the national average of $8 \%$ (Gibbons, 2005b).

Finally, when asked about paying for their college education, 22.3\% indicated that scholarships covered most or all of their expenses. Additionally, 23.1\% of participants reported engaging in fraternity or sorority activities at least 1 hour per week, while $71.5 \%$ of respondents reported participating in clubs, student teams, professional societies, and/or community service organizations at least 1 hour per week.

\section{Instruments and Variables}

The Perceptions and Attitudes toward Cheating among Engineering Students Survey, version 2 (PACES-2) and the Defining Issues Test, version 2 (DIT-2) were administered to students during several sessions held at the three participating institutions. The PACES-2 Survey was developed by the authors and consists of items to assess the constructs of the modified Theory of Planned Behavior. The dependent variables investigated for this study included frequency of test cheating in college (test cheating) and frequency of homework cheating in college (homework cheating). Using a five-point Likert scale, respondents were asked to indicate, "During the previous academic term in college, how frequently did you cheat on in-class tests or exams?" For homework cheating, respondents were asked, "During the previous academic term in college, how frequently did you cheat on homework assignments?” Responses to these items included:

- $\quad$ Never (1),

- A few of the times I took a test or exam/worked on a homework assignment (2),

- About half the times I took a test or exam/worked on a homework assignment (3),

- Almost every time I took a test or exam/worked on a homework assignment (4),

- Every time I took a test or exam/worked on a homework assignment (5). 
It is worth noting that the wording of these items does not define cheating for the respondent. Instead, we allowed the individual respondents to define this term themselves. As such, the items measure the extent to which the respondents acknowledged engaging in a behavior they recognize as cheating and therefore (by assumption) unethical. In this way, the measures of cheating used in this study are conservative but are assessing an act that the respondent defines as unethical, thereby avoiding the difficulty of defining cheating.

Further, the wording for these items requires the respondents to consider the frequency with which they cheat, thus accounting for potential differences in number of opportunities to engage in cheating that students may experience. Students were also asked to indicate the number of times they had cheated on a test and on a homework assignment in the last term in separate survey items. The frequency and number items were highly correlated for both test and homework contexts ( 0.90 and 0.82 respectively), providing support for the validity of the frequency items.

The PACES-2 instrument also includes a number of items measuring the constructs in the modified version of the Theory of Planned Behavior (i.e. intention, attitude toward behavior, subjective norm, perceived behavioral control, and moral obligation). All items are measured using 5-point Likert scales, except in the case of attitude toward the behavior which is measured with a series of 7-point semantic differential scales. Similar to the behavioral items described previously, all construct related items were posed in two separate contexts: test and homework. The Balanced Inventory of Desirable Responding (BIDR) instrument (Paulhus, 1991) is included verbatim at the end of the PACES-2 Survey to control for social desirability bias.

The DIT-2 was originally developed by Rest (Rest \& Narvaez, 1994; Rest et al., 1999b) and is based on Kohlberg's Theory of Moral Development (1976, 1981), suggesting that individuals who adopt a principled approach to resolving moral issues understand fairness and justice as systems that serve anonymous others. Respondents are asked to rate and rank prescribed statements most closely aligned with how they reason when faced with five hypothetical moral dilemmas. Higher DIT-2 scores reflect an individual's increased capacity for reasoning about moral issues based on a system of fairness that serves the public good; lower DIT-2 scores tend to reflect reasoning about moral issues from a self-serving understanding of fairness. The DIT-2, and its predecessor the DIT, purport to measure only the moral reasoning component of what constitutes moral development; as such it is susceptible to change over time. The DIT is generally considered to be among the most valid instruments for measuring moral reasoning aptitude (Rogers, 2002).

The two-part survey instrument was pilot tested at School A to develop reliable, internallyconsistent scales for the PACES-2 Survey and to identify shortcomings in study protocols. This pilot testing was followed by a second test-retest phase at School A to establish the temporal stability of the questionnaire items. The final phase of the study involved the full administration of the PACES-2 and DIT-2 survey instruments to the study populations at all three schools. A total of 1600 randomly selected students from the three institutions were recruited to participate in the final phase of the study - 800 from School A, and 400 each from Schools B and C. A number of approaches were used to increase response rate as described elsewhere (Finelli et al, 2005). Response rate varied by institution - 27.9\% for School A, 52.0\% for School B, and $24.0 \%$ for School C. All instruments and methods described here were reviewed and approved by a behavioral sciences institutional review board. 
Analyses

Confirmatory factor analysis was conducted using principle axis factoring and orthogonal rotation methods for the constructs described above. Results of this analysis are shown in Table 1. When necessary, items were reverse coded for ease in interpretation. Only factors with eigenvalues greater than 1.0 were used in the final model. Factor loadings of at least 0.38 or higher were used in the development of subsequent summated scales. Internal consistency for each of these scales was moderate to high, with Cronbach's alpha reliabilities reaching at least 0.67 (see Table 1).

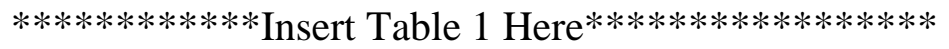

In addition to the factor analysis described above, a series of descriptive analyses were performed. T-tests were used to compare the dependent variables (college cheating frequency) across the various sub-groups within the sample. In addition, bivariate correlational and multiple regression analyses were performed. Because the dependent behavior variables failed normality tests, they were transformed to dichotomous variables using a median split for the correlation and regression analysis.

The operational model developed for this study (see Figure 1) includes paths between independent and dependent variables that introduce the possibility of mediating effects. For example, the intention construct may mediate the effects of selected demographic variables including past behavior on the dependent variable of college cheating behavior. According to the model, an individual who cheated frequently on tests in high school is more likely to form an intention to cheat on tests in college, which in turn causes him/her to cheat more often on tests in college. Here, the effect of intention mediates the effect of high school test cheating on college test cheating.

Specifically, mediation can occur when the independent variable shares a significant relationship with both the mediating variable and the outcome and when the mediating variable shares a significant relationship with the outcome (Preacher \& Leonardelli, 2004). In order to assess the potential mediating effects of intention, the Goodman 1 version of the Sobel test of mediating effects (Baron \& Kenny, 1986) was performed. This version of the Sobel test was chosen based on criteria developed by Preacher and Leonardelli (2004) and MacKinnon, Warsi, and Dwyer (1995). This version is recommended for sample sizes greater than fifty, never yields negative variance estimates, and does not make any unnecessary assumptions concerning the products of standard errors. For a detailed discussion of these criteria, see Preacher and Leonardelli (2004).

\section{RESULTS}

\section{Behavioral Measures}

On average, respondents self-reported cheating less than a few of the times they took a test and less than a few of the times they worked on a homework assignment during the previous academic term. Further, $28.7 \%$ and $54.5 \%$ of the respondents reported they had cheated at least once during the previous term for the test and homework context respectively. Engineering students reported cheating at significantly higher frequencies for both test $(p<0.01)$ and homework cheating $(\mathrm{p}<0.001)$ compared to humanities students, suggesting that even when accounting for number of opportunities, engineering students within this sample report cheating on tests more frequently. Unlike the self-reported frequency of college cheating for the test and homework contexts, the reported frequency of past (i.e., high school) cheating is not significantly 
different ( $\mathrm{p}>0.05)$ for engineering and humanities students in either context. When this finding is considered in conjunction with the disciplinary differences in self-reported college cheating, it is obvious that the differences occur after students arrive at college (and select a disciplinary major), not before, suggesting an influence of college discipline.

For this study, seniors reported being somewhat less likely to engage in college-level cheating. For example, in the case of test cheating, $24.4 \%$ of seniors admitted to cheating on at least a few of their tests during the last academic term, while 31.4\% of freshmen admitted to doing so.

Likewise, for homework $49.5 \%$ of seniors reported cheating on at least a few assignments in the last term, while $57.1 \%$ of freshmen reported doing so. Neither of these differences, however, is statistically significant.

Only in the case of past cheating is there a statistically significant difference in reported cheating frequencies between seniors and freshmen, the most notable being the case of homework cheating in high school. Approximately $75 \%$ of freshmen in this study reported cheating on at least a few homework assignments during an average high school term, compared to only 55\% of seniors. This difference is significant $(\mathrm{p}<0.001)$, though the effect size is moderate at $\mathrm{d}=0.38$. There is also a large difference in reported frequency of test cheating in high school with 55\% and $42 \%$ of freshmen and seniors, respectively, reporting that they cheated on at least a few inclass tests during an average high school term, but this difference is not significant.

\section{Modified Theory of Planned Behavior}

Correlation tables for the constructs underlying the Theory of Planned Behavior and the behavioral variables are shown in Tables 2 and 3 for test and homework cheating respectively. As can be seen, all of the underlying constructs are significantly correlated with the behavioral variables. Most notably, the intention construct is strongly correlated with self-reported frequencies of cheating for both test and homework cheating in college. This is in agreement with the Theory of Planned Behavior that predicts that intention is a direct antecedent to engagement in a behavior. Frequency of past cheating is moderately correlated with college cheating, which was also predicted by our modified form of the theory. It should also be noted that the second order constructs in the modified Theory of Planned Behavior (attitude, subjective norm, perceived behavioral control, and moral obligation) are correlated with the behavioral variable, though to a lesser extent than intention. Due to the scoring scheme employed, a positive correlation between the moral obligation score and cheating behavior implies that individuals with less sense of obligation to behave unethically will be more likely to cheat. For this study, all constructs were coded such that higher scores would theoretically imply greater cheating.

*************** Insert Tables 2 and 3 Here $* * * * * * * * * * * * * * * *$

The socially desirable responding (BIDR) and moral reasoning (DIT-N2) scores of the respondents are inversely correlated to the behavioral variables, but only weakly. This result is not unexpected. A higher BIDR score would indicate that a person is more likely to give socially desirable responses to a questionnaire and would thus be expected to report lower frequencies of cheating than their peers. Likewise, a higher N2 score indicates that an individual uses more principled reasoning. Such an individual would probably view cheating as unfair to anonymous others and would be less likely to do so; therefore reporting a lower frequency of cheating. 
The high correlations ( $r=0.56-0.69)$ between moral obligation, attitude toward behavior, and subjective norm for both the test and homework contexts are similar to those reported by other researchers investigating the use of the Theory of Planned Behavior in predicting dishonest behaviors (Beck \& Ajzen, 1991). However, such high correlations indicate potential problems with multicollinearity, a situation in which predictor variables, which are presumed to be independent, are actually highly correlated suggesting they measure similar phenomenon. As such, the authors reduced these constructs via a second-order factor analysis to a single factor that incorporated measures of all three. Factor loadings are shown in Table 4. Regardless of context, $77 \%$ of the variance in these measures was explained by the single factor, with a Cronbach's alpha of 0.85 , providing reassurance that a single, second-order factor model was valid and reliable.

****************** Insert Table 4 Here $* * * * * * * * * * * * * * * * *$

\section{Cheating Behavior Regression}

Table 5 presents unstandardized regression coefficients for the model in both contexts - test and homework cheating - allowing for direct comparison of the two models. Levels of variance $\left(\mathrm{R}^{2}\right)$ explained for test and homework cheating were $39 \%$ and $27 \%$ respectively, indicating that the model is moderately successful in predicting respondents' behavior. The model predicted intention with a high degree of accuracy, explaining $58 \%$ of the variance in the model for both the test and homework contexts. These values for variance explained are similar to those reported in the literature on the Theory of Planned Behavior (Beck \& Ajzen, 1991; Conner \& Armitage, 1998) supporting the use of the theory as a model of cheating behavior. Further, percentage of variance explained for intention, and to a lesser extent behavior, was similar for both homework and test contexts.

\section{Insert Table 5 Here}

As predicted by the Theory of Planned Behavior, an individual's intention to engage in cheating had a significant influence on his/her self-reported college cheating behavior. The values of the regression coefficient for intention ( $\mathrm{b}=0.219, \mathrm{p}<.0001$ ) were identical for both test and homework contexts, suggesting that the importance of this variable on behavior may be independent of context. However, perceived behavioral control failed to predict behavior, suggesting that participants’ perceived ease of cheating has little bearing on their actual cheating.

Not surprisingly, past behavior (i.e. high school cheating) was a strong predictor of college cheating, with students who reported cheating more frequently in high school reporting a higher frequency of cheating in college. However, past behavior seems to have a slightly greater influence in the test context $(b=0.130, \mathrm{p}<.0001)$ than in the homework context $(b=0.076$, $\mathrm{p}<.01)$.

Among the demographic variables, discipline (engineering or humanities) had a significant influence on the participants self-reported cheating for both test $(b=-0.130, p<.01)$ and homework ( $b=-0.108, p<.05$ ), with engineering students being more likely to self-report cheating as expected. As the coefficients indicate, the strength of this relationship was slightly stronger for the test context. Further, in the case of test cheating, gender seems to play a significant role with increased test cheating reported among female students $(b=.120, p<.01)$. Gender does not, however, play a significant role in explaining the variance in homework cheating. 
Finally, according to the regression coefficients, test cheating behavior was slightly lower (b=0.059, $\mathrm{p}<.05$ ) for those students who reported paying for all or most of their college expenses through scholarships. However, closer examination of the data shows that the relationship between scholarships and cheating behavior is non-linear. Students who received most or all of their tuition support through scholarship, as well as those who received none, were least likely to cheat on a test with slightly more than $25 \%$ of these students indicating they had cheated at least a few of the times they had taken a test. On the other hand, students who paid some of their tuition through scholarship were most likely to cheat with $31 \%$ of these students indicating they had cheated at least a few of the times they had taken a test. Students who paid some of their tuition also represented $64 \%$ of the sample. As such, the authors are skeptical as to the validity of the regression results in this case.

\section{Intention Regression}

As predicted by the Theory of Planned Behavior, the second-order factor (i.e., combination of moral obligation, attitude toward the behavior, and subjective norms) was a significant predictor of an individual's intention to cheat. Further, the strength of the regression coefficient was similar for both the test and homework contexts $(b=0.662$ vs. 0.643$)$, suggesting that the combined effect of attitude, subjective norm, and moral obligation on cheating behavior may be independent of context. Similar to the regression of perceived behavioral control onto cheating behavior, perceived behavioral control failed to have a significant effect for either context.

Past behavior was a significant predictor of intention, with respondents who reported more frequent high school cheating also having a stronger intention to cheat in the current academic term. This relationship was considerably stronger in the context of test cheating. Interestingly, the magnitude of the past behavior regression coefficient is approximately $70 \%$ larger for the test context when regressed onto both behavior and intention, implying that an individual's intention to engage in presumably more risky unethical behaviors (i.e. test cheating) is more strongly influenced by their past behavior than in instances where the behavior is less risky (i.e. homework cheating).

Once again, discipline was an important variable in explaining the variance in both the test and homework regression models, with engineering students being more likely to form an intention to cheat than humanities students. As seen in the regression on the dependent behavioral measures, discipline was a stronger predictor of intention in the test context $(b=-0.254)$ than it was in the homework context $(b=-0.173)$.

Membership in a fraternity or sorority was a significant predictor of intention to cheat for both the test and homework contexts. However, membership in a fraternity/sorority did not influence actual cheating behavior, suggesting that while fraternity and/or sorority members may be more likely to intend to cheat, they are no more likely to actually do so. Also, freshmen were somewhat more likely to intend to cheat on homework than were the seniors included in this study, though again this did not seem to affect their actual behavior.

\section{Influence of Moral Reasoning}

The model hypothesized by the authors indicates that moral reasoning should act as an antecedent variable of moral obligation. The negative regression coefficient $(b=-.013, p<.0001)$ between moral reasoning and the second-order factor suggests that respondents with higher measured moral reasoning scores tended to have lower second-order factor scores. This result is 
in the expected direction since higher scores on any one of the Theory of Planned Behavior constructs implies a greater likelihood to cheat. Thus one might conclude that students who are more likely to base their understandings of fairness on conceptions of justice that serve societal needs (high moral reasoning scores) are significantly more likely to feel some sense of moral obligation to avoid cheating, less positive attitudes toward cheating, and be more sensitive to subjective norms against cheating (low second-order factor scores). Finally, the strength of the relationship between moral reasoning and the second-order factor appears to be independent of the context.

\section{Indirect Effects}

Within the model proposed in this study, the direct effects of several variables on the dependent behavioral measures have the potential to be mediated by intention. Specifically, selected demographic variables including past behavior and perceived behavioral control each have an indirect relationship with behavior through intention. Table 5 shows the regression coefficients determined from an analysis of these indirect relationships. As discussed previously, the significance of these relationships was determined using the Sobel Test (Baron \& Kenny, 1986). This data shows that the effects of both discipline and past cheating behavior are mediated by intention in the expected directions. As seen in the direct effects, the strengths of the regression coefficients are generally larger in the test context. Also, fraternity membership had a small indirect effect on behavior through intention. This is not surprising considering that fraternity membership was shown to have a direct effect on intention but not behavior.

\section{LIMITATIONS}

Though the authors feel that this study has made significant contributions to the literature on student ethical decision-making and cheating, particularly within the engineering discipline, there are certain limitations to this study that constrain the degree to which the results can be generalized. First, this study took place at three institutions, and although these vary by institutional type, generalizations of the findings from this study should be approached with caution. While sample sizes were sufficient for statistical power, they represent only a small fraction of the population of interest, limiting the ability to extend conclusions to the general population of engineering and humanities undergraduates, much less all undergraduates. Also, due to sample limitations, we were unable to examine how phenomena related to cheating behaviors (e.g., expectations, standards, histories) differed for students from varying racial and ethnic backgrounds. In addition, although parameter estimates of a structural model (i.e., path coefficients for direct and indirect effects) are reported here, the authors did not use structural equation modeling software programs to generate goodness of fit indicators for assessing how well our data fit our modified version of Ajzen's Theory of Planned Behavior. Such an analysis would be a fruitful venue for future research and provide more evidence of the validity of the Theory of Planned Behavior in mapping students’ ethical decision-making processes.

\section{DISCUSSION}

This study has confirmed the use of a modified form of the Theory of Planned Behavior as a model of the decision-making process used by engineering and humanities students when they consider engaging in cheating in two contexts - completing a test and homework assignment, respectively. Of particular note is the model's inclusion of moral obligation and reasoning in conjunction with constructs constitutional to the original Theory of Planned Behavior for predicting intention to cheat and how this inclusion increased our understanding of the 
multifaceted nature of ethical decision-making and behaviors. In addition, path coefficients relating intention to behavior were significant and positive, supporting Ajzen's (1991) seminal thinking about the nature and predictability of behavior. Successful prediction of these constructs is compelling evidence for using this modified form of the Theory of Planned Behavior, especially when trying to understand cheating intention and behavior.

Though multicollinearity issues prohibit us from distinguishing the independent effects of moral obligation, attitude toward the behavior, and subjective norm, these constructs were shown to play an important role in establishing an individual's intention to engage in cheating. These results are consistent with those of Whitley (1998) and imply that students who exhibit a more positive attitude toward cheating, who operate in an environment with less restrictive norms against cheating, and who have a weak sense of moral obligation to avoid cheating will be more likely to cheat in a given situation.

The Theory of Planned Behavior construct of perceived behavioral control was not significantly related to either intention or behavior. At first glance, this seems to imply that students' perceptions of the relative difficulty of cheating on tests and homework have no effect on their intention to do so or their reported engagement in these behaviors. However, some questions remain about how respondents interpreted the survey items themselves, and whether the items measured perceived behavioral control as described by Ajzen (2002) or some other psychological construct such as self-efficacy. Further research is needed in this area before perceived behavioral control can be removed from the model.

Equally important, the relative magnitudes of the variance explained for the models of cheating in both contexts (tests and homework) were similar. The unstandardized regression coefficients for the key constructs within the Theory of Planned Behavior were also equal across both contexts. Together these results suggest that the Theory of Planned Behavior is a robust model of the self-reported cheating behaviors of the undergraduates included in this study and the formation of their intention to cheat irrespective of the context (i.e. tests and homework). This general conclusion provides support for further research on the use of this modified version of the Theory of Planned Behavior as a predictive and explanatory model of ethical decisionmaking among undergraduates.

Another finding of this research was that high school cheating was an important predictor of both college cheating and intention to cheat. This finding supports previous work that showed that past cheating is related to unethical behavior later in life (Nonis \& Swift, 2001; Sims, 1993). In our own work, we have found that students who engage in cheating in college are significantly more likely to engage in behaviors that violate the policies of their professional workplaces (Harding et al, 2004a). This relationship was only strengthened for those students who reported frequently cheating in high school. Thus, a behavioral pattern emerges that for those students who behave unethically early in their lives, such behaviors are more likely in a variety of settings.

The indirect effect of past behavior on college cheating behavior as mediated by intention is not surprising. One would expect that a student who cheated frequently in high school would feel that this was a normal approach to succeeding in educational endeavors. Such a student would easily form stronger intentions to cheat, and this increased intention would lead to a greater propensity for cheating. It is not the case, though, that a student who cheated more frequently in high school developed a stronger sense of efficacy in the behavior, as past behavior is only 
weakly correlated with perceived behavioral control (see Tables 2 and 3). Thus, the mediating effect of intention on the relationship between past and present behavior seems to be related more to an individual's enhanced sense of the possible positive outcomes of cheating, rather than any increased sense of skill at cheating. Alternatively, why past cheating should directly affect one's behavior in college remains unclear. Further work is needed to better understand how an individual's actions in the past can alter their attitudes, beliefs, and expectancies such that they would more willingly engage in the behavior again in the future.

The results also confirmed previously observed differences in the rates of cheating between engineering students and those from other disciplines, in this case humanities. One distinctive contribution of this study was to show, at least for this particular sample, that this difference occurs regardless of the number of opportunities to cheat experienced by an individual student. Furthermore, the difference in rates of cheating between engineering and humanities students was shown to exist only in college, not in high school, and discipline remained an independent predictor of both behavior and intention, even after controlling for the other constructs of the modified theory. Together these results indicate that the explanation for higher rates of cheating among engineering students may lie outside the constructs included in this study. Perhaps engineering programs and curricula are more rigorous and/or more competitive than those of other disciplines; such cultural attributes may drive engineering students to cheat to a greater degree than other students. Another reason for the disparity between humanities and engineering may lie in the nature of the varying approaches to assessment faculty use to measure student learning. Perhaps, humanities faculty are more likely to adopt more subjective, less standardized homework assignments and tests for evaluating student performance where engineering faculty may use more objective approaches. These differences may play on students' perceptions of their learning environments as ones where cheating is easier, or in their minds, more necessary. Differences between engineering and humanities students may also be due to curricular differences in dealing with ethics education. In engineering ethics and ethical decision-making are rarely discussed within the context of students' everyday lives. Instead most engineering ethics experiences focus either on prescriptive codes of conduct or engineering disasters, neither of which have a great deal of relevance to most engineering undergraduates, particularly within the context of cheating. Results of the current study cannot confirm these hypotheses, and as such further work is needed to explore the influence of discipline specific factors on students' ethical decision-making and behavior.

While no statistically significant difference was found in the college cheating behavior of freshmen and seniors, we did not anticipate such a dramatic difference in reported high school cheating frequencies between these groups. One possible explanation for this difference is a temporal effect in which the greater difference of time between the events under question and the survey itself for the seniors reduces their response. In other words, over the course of time, the seniors have created an artificially positive perception of the extent of their own cheating while in high school. An equally valid explanation could be that the freshmen in this study actually did cheat more often in high school. This could be due to a general decline in ethical standards among today's high school students as reported in the popular media, but the authors are skeptical that such large changes could occur over only four years. Alternatively, it could be the result of a gradual shift in the make-up of the senior student population as less capable and/or motivated students who may have cheated more frequently in high school drop-out or change majors prior to reaching senior status. 
The data confirmed the prediction of the modified Theory of Planned Behavior proposed in this study, that moral reasoning - as defined by Kohlberg $(1976,1981)$ - would have a direct effect on an individual's moral obligation scores. This may suggest that moral reasoning and moral obligation act in sequence, one following the other and would seem logical given that as one increasingly organizes their relationships with others around higher moral principles, they would also be more likely to feel obligated to avoid behaviors that are viewed as unfair or unjust to anonymous others. Given the second-order factor's relative importance in determining an individual's intention in this study, the means by which moral reasoning influences moral obligation (and perhaps the other elements of the second-order factor) warrants further investigation.

However, this study did not include the other three components of Rest's Four Component Model (Rest \& Narvaez, 1994): moral sensitivity, moral motivation, and moral character. As Rest pointed out, it is more likely that these concepts relate in a complex set of interactions that ultimately lead to a moral intention rather than in any sequential fashion. Any attempt to understand moral reasoning's influence on moral obligation, intention, and behavior should ultimately include these other components. In addition, the current research ignores important developments in the socio-cognitive realm in recent years, most notably the concept of moral identity. Moral identity, based on the work of Blasi (1984) and others, can be considered a means of organizing one's self-concept in a way that provides the motivation to promote the welfare of others (Hart, Atkins \& Ford, 1998). Here the motivating influence provided by moral identity is free to vary with context as well as in its impact on the individual's actions. By including a measure of moral identity to the model such that it can be influenced by the contextual variables in this study, we might yet find a stronger set of relationships between moral reasoning, moral obligation, intention, and behavior.

One strength of this research is its use of a theoretical foundation to examine not just ethical reasoning, but actual ethical behavior. Higher education researchers need to account for the theoretical relationships between constructs when designing and executing research on students. If the research community neglects theoretical relationships and studies of this sort, it runs the risk of failing to contribute to the systematic knowledge (hypothesis testing, replication, theory construction) needed to affect change. This study has provided evidence to support one such theoretical roadmap that may be useful in planning future research studies. Second, this study provides educators interested in moral education one potential theory for understanding the underlying psychological mechanisms involved in students' decisions to cheat and that may subsequently lead to more effective curricular interventions that help students develop their capacities for ethical decision-making and behavior. Only by discovering how theoretical elements (i.e., moral reasoning and constructs constituting the Theory of Planned Behavior) function together to influence ethical decision-making and behaviors can we as educators ever hope to matriculate students who understand and share in the great responsibility for contributing to society's moral health. 
Figure 1: Modified version of Ajzen's Theory of Planned Behavior (Ajzen, 1991; Ajzen, 2002)

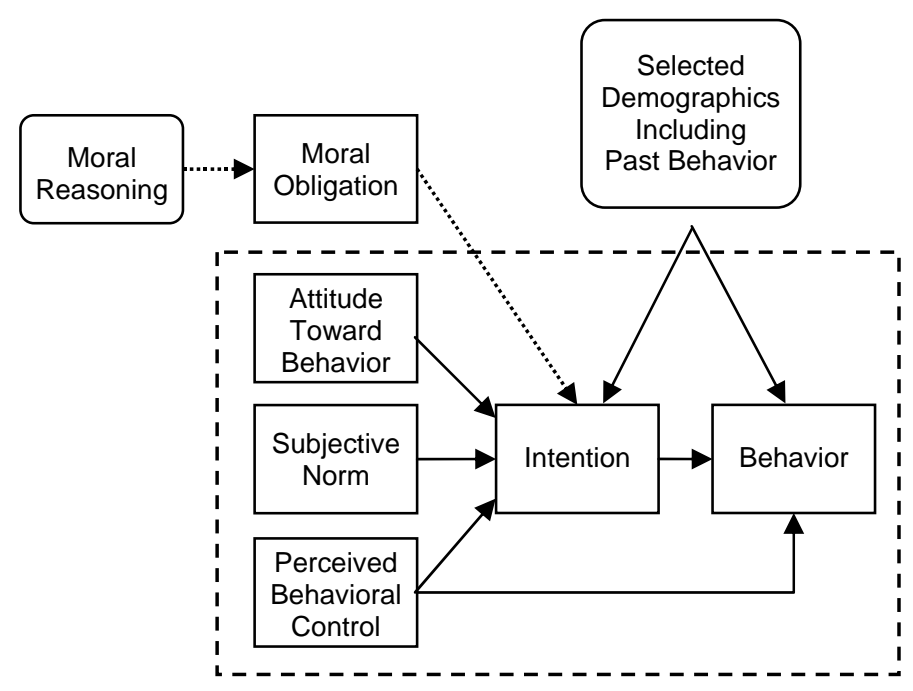

Figure 2: Cross-sectional $(2 \times 2 \times 2)$ design of the PACES-2 study including discipline, class level, and cheating context.

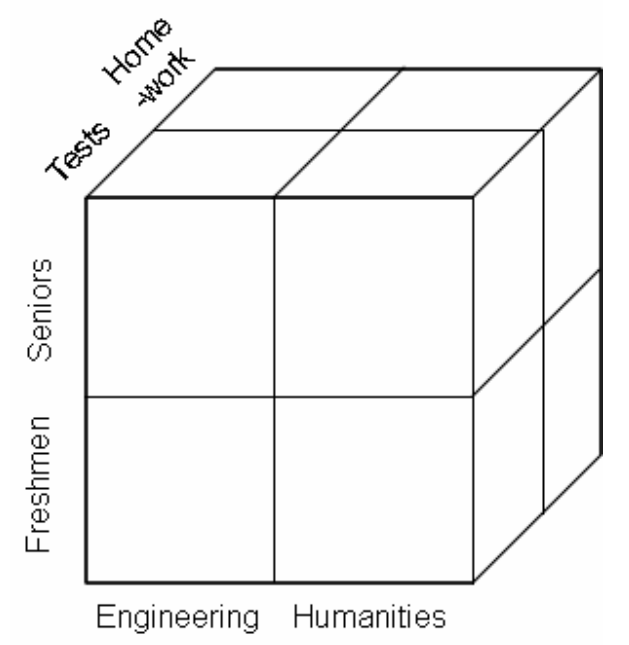




\begin{tabular}{|c|c|c|}
\hline \multirow[t]{3}{*}{ Factor and Survey Items } & \multicolumn{2}{|c|}{ Factor Loading } \\
\hline & Testing & Homework \\
\hline & Context & Context \\
\hline Intention ${ }^{a}$ (alpha) & $(.918)$ & $(.940)$ \\
\hline I will try to cheat on an in-class test or exam* during the current academic term & .886 & .913 \\
\hline I intend to cheat on an in-class test or exam* during the academic term & .884 & .916 \\
\hline I do NOT plan to cheat on an in-class test or exam* during the academic term ${ }^{\circledR}$ & .884 & .900 \\
\hline I will NOT cheat on an in-class test or exam*during the current academic term ${ }^{\circledR}$ & .866 & .883 \\
\hline $\begin{array}{l}\text { If I had the opportunity, I would cheat on an in-class test or exam* during the } \\
\text { current academic term }\end{array}$ & .830 & .868 \\
\hline Attitude toward behavior ${ }^{b}$ (alpha) & (.769) & $(.837)$ \\
\hline Positive to Negative & .858 & .886 \\
\hline Good to Bad & .825 & .866 \\
\hline Pleasant to Unpleasant & .810 & .827 \\
\hline Superior to Inferior & .729 & .852 \\
\hline Thrilling to Boring & .375 & .394 \\
\hline Subjective norms ${ }^{a}$ (alpha) & (.855) & $(.892)$ \\
\hline $\begin{array}{l}\text { If I cheated on an in-class test or exam*, most of the people who are important to } \\
\text { me (e.g., my family, friends, colleagues, teachers, etc.) would approve of my } \\
\text { behavior }\end{array}$ & .804 & .832 \\
\hline $\begin{array}{l}\text { The people in my life whose opinions I value (e.g., my family, friends, colleagues, } \\
\text { teachers, etc.) would be willing to cheat on an in-class test or exam* if they } \\
\text { were in my situation }\end{array}$ & .799 & .837 \\
\hline $\begin{array}{l}\text { Most people who are important to me (e.g., my family, friends, colleagues, } \\
\text { teachers, etc.) would be willing to cheat on an in-class test or exam* if they } \\
\text { were in my situation }\end{array}$ & .790 & .835 \\
\hline $\begin{array}{l}\text { The people in my life whose opinions I value (e.g., my family, friends, colleagues, } \\
\text { teachers, etc.) would NOT approve if I cheated on an in-class test or exam* }{ }^{\circledR}\end{array}$ & .722 & .779 \\
\hline $\begin{array}{l}\text { Most people who are important to me (e.g., my family, friends, colleagues, } \\
\text { teachers, etc.) think I should NOT cheat on an in-class test or exam* }{ }^{\circledR}\end{array}$ & .709 & .728 \\
\hline $\begin{array}{l}\text { People whose opinions I value (e.g., my family, friends, colleagues, teachers, etc.) } \\
\text { expect me to cheat on an in-class test or exam* }\end{array}$ & .656 & .740 \\
\hline $\begin{array}{l}\text { Most people who are important to me (e.g., my family, friends, colleagues, } \\
\text { teachers, etc.) will look down on me if I cheat on an in-class test or exam* }{ }^{\circledR}\end{array}$ & .631 & .760 \\
\hline $\begin{array}{l}\text { NO ONE who is important to me (e.g., my family, friends, colleagues, teachers, } \\
\text { etc.) thinks it is OK to cheat on an in-class test or exam*® }\end{array}$ & .616 & .599 \\
\hline Perceived behavioral control ${ }^{a}$ (alpha) & $(.667)$ & $(.765)$ \\
\hline $\begin{array}{l}\text { I believe that I would have a great deal of control over whether I get caught } \\
\text { attempting to cheat on an on-class or test exam* }\end{array}$ & .794 & .840 \\
\hline $\begin{array}{l}\text { I believe that I have the skills needed to cheat on an in-class test or exam* in all } \\
\text { circumstances }\end{array}$ & .736 & .771 \\
\hline $\begin{array}{l}\text { It is mostly up to me whether or not I successfully cheat on an in-class test or } \\
\text { exam* }\end{array}$ & .723 & .804 \\
\hline Even if I wanted to, I could NOT cheat on an in-class test or exam* ® & .575 & .614 \\
\hline Moral obligation ${ }^{a}($ alpha) & $(.848)$ & $(.864)$ \\
\hline Cheating on an in-class test or exam* is against my principles ${ }^{\circledR}$ & .898 & .920 \\
\hline I would feel guilty if I cheated on an in-class test or exam*® & .868 & .893 \\
\hline It would NOT be morally wrong for me to cheat on an in-class test or exam* & .860 & .848 \\
\hline
\end{tabular}

* Indicates wording change from in-class test or exam to homework assignment for questions asked for cheating in the context of homework.

( Indicates items that were reversed-scored.

$a=5$-point scale: From $1=$ Strongly agree to $5=$ strongly disagree

$\boldsymbol{b}=7$-point semantic differential scale: From 1 = extremely closely related to $7=$ extremely closely related 
Table 2: Correlations for Theory of Planned Behavior Constructs for Test Cheating in College

$\begin{array}{lllllllll}1 & 2 & 3 & 4 & 5 & 6 & 7 & 8 & 9\end{array}$
1) Test Cheating
2) Past Test
Cheating

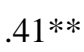
3) Intention
$.62 * * \quad .38 * *$
4) Attitude
$.39 * *$
$.26 * * \quad .62 * *$
5) Subjective
Norm
$\begin{array}{llll}.32 * * & .23 * * & .59 * * & .56 * *\end{array}$
6) $\mathrm{PBC}$
$.15^{* *}$
$.10^{*}$
$.23^{* *} \quad .28 * * \quad .28 * *$
7) Moral
Obligation
$.40^{* *} \quad .37^{* *} \quad .71^{* *} \quad .69^{* *}$
$.65 * *$
$.34 * *$
8) BIDR Score
$-.20 * * \quad-.23 *$
$-.36 * * \quad-.36 * *$
$-.29 * *$
$-.18 * * \quad-.35 * *$
9) N2 Score
$-.21 * * \quad-.12 *$
$-.24 *$
$-.18^{* *}-.18^{* *}$
$-.09-.21^{* *}$
$.15^{* *}$

- Perceived Behavioral Control

$+\mathrm{p}<.10,{ }^{*} \mathrm{p}<.05,{ }^{* *} \mathrm{p}<.01,{ }^{* * *} \mathrm{p}<.0001$

Table 3: Correlations for Theory of Planned Behavior Constructs for Homework Cheating in College

$\begin{array}{lllllllll}1 & 2 & 3 & 4 & 5 & 6 & 7 & 8 & 9\end{array}$
1) Homework
Cheating
2) Past HW
Cheating
$.36 * *$
3) Intention
$.56 * * \quad .38 * *$
4) Attitude
$.44 * *$
$.26 * *$
$.64 * *$
5) Subjective
$.31 * *$
$.21 * *$
$.64^{* *} \quad .61^{* *}$
Norm
$.13^{* *} \quad .14^{* *}$
$.26 * * \quad .29 * *$
$.31 * *$
7) Moral
Obligation
$\begin{array}{lllll}.39 * * & .34 * * & .70 * * & .69 * * & .69 * *\end{array}$
$.35 * *$
8) BIDR Score
$-.22 * * \quad-.26 * *$
$-.37 * *$
$-.36 * *$
$-.29 * *$
$-.12 * *$
$-.36^{* *}$
9) N2 Score
$-.18 * * \quad-.11 *$
$-.21 * *$
$-.18 * *$
$-.10 *$
.02
$-.18 * * \quad .15 * *$

- Perceived Behavioral Control

$+\mathrm{p}<.10,{ }^{*} \mathrm{p}<.05,{ }^{* *} \mathrm{p}<.01,{ }^{* * *} \mathrm{p}<.0001$ 
Table 4: Items, Factor Loadings, and Reliabilities for Second Order Factor

\begin{tabular}{lcc}
\hline Factor and Survey Items & \multicolumn{2}{c}{ Factor Loading } \\
\hline & Testing & Homework \\
Context
\end{tabular}

$a^{a}=5$-point scale: From $1=$ Strongly agree to $5=$ strongly disagree

$\boldsymbol{b}=7$-point semantic differential scale: From $1=$ extremely closely related to $7=$ extremely closely related 
Table 5: Unstandardized Regression Coefficients Predicting Frequency of Cheating on Tests and Frequency of Cheating on Homework

\begin{tabular}{|c|c|c|}
\hline Direct effects on: & $\begin{array}{c}\text { Frequency of Cheating } \\
\text { on Tests }\end{array}$ & $\begin{array}{c}\text { Frequency of Cheating on } \\
\text { Homework }\end{array}$ \\
\hline Behavior & $\mathrm{R}^{2}=0.390$ & $\mathrm{R}^{2}=0.267$ \\
\hline \multicolumn{3}{|l|}{ Demographics } \\
\hline Education level (Freshman) & -.013 & -.004 \\
\hline Investment Scholarship & $-.059 *$ & .008 \\
\hline Fraternity membership (No) & .057 & .067 \\
\hline Club membership (No) & -.032 & .064 \\
\hline International student (No) & .058 & .006 \\
\hline Gender (Male) & $.120 * *$ & .048 \\
\hline Discipline (Engineering) & $-.130 * *$ & $-.108^{*}$ \\
\hline Past Behavior & $.130 * * *$ & $.076^{* *}$ \\
\hline Perceived Behavioral Control & .025 & -.016 \\
\hline Intention & $.219 * * *$ & $.219 * * *$ \\
\hline Intention & $\mathrm{R}^{2}=0.577$ & $\mathrm{R}^{2}=0.581$ \\
\hline \multicolumn{3}{|l|}{ Demographics } \\
\hline Education level (Freshman) & -.007 & $-.145 *$ \\
\hline Investment Scholarship & .003 & .015 \\
\hline Fraternity membership (No) & $.164 *$ & $.173 *$ \\
\hline Club membership (No) & -.004 & .067 \\
\hline International student (No) & -.003 & .175 \\
\hline Gender (Male) & -.003 & -.106 \\
\hline Discipline (Engineering) & $-.254 * *$ & $-.173^{*}$ \\
\hline Past Behavior & $.336 * * *$ & $.201 * * *$ \\
\hline Perceived Behavioral Control & .001 & .019 \\
\hline $\begin{array}{l}\text { Second order factor (Moral Obligation, Attitude Toward } \\
\text { Behavior, Social Norms) }\end{array}$ & $.662 * * *$ & $.643^{* * *}$ \\
\hline $\begin{array}{l}\text { Second order factor (Moral Obligation, Attitude Toward } \\
\text { Behavior, Social Norms) }\end{array}$ & $\mathrm{R}^{2}=0.031$ & $\mathrm{R}^{2}=0.031$ \\
\hline Moral Reasoning & $-.013 * * *$ & $-.013 * * *$ \\
\hline \multicolumn{3}{|l|}{ Indirect effects on: } \\
\hline \multicolumn{3}{|l|}{ Behavior } \\
\hline \multicolumn{3}{|l|}{ Demographics } \\
\hline Education level (Freshman) & -.003 & -.001 \\
\hline Investment Scholarship & -.013 & .002 \\
\hline Fraternity membership (No) & $.012^{*}$ & .015 \\
\hline Club membership (No) & -.007 & .014 \\
\hline International student (No) & .013 & .001 \\
\hline Gender (Male) & .026 & .011 \\
\hline Discipline (Engineering) & $-.029 *$ & $-.024 *$ \\
\hline Past Behavior & $.029 * * *$ & $.017^{* *}$ \\
\hline Perceived Behavioral Control & .005 & -.004 \\
\hline
\end{tabular}




\section{REFERENCES}

Ajzen, I. (1991). The Theory of Planned Behavior. Organizational Behavior and Human Decision Processes, 50, 179-211.

Ajzen, I. (2002). Attitudes, Personality, and Behavior. Buckingham: Open University Press.

Armitage, C.J., \& Conner, M. (1999). Predictive validity of the theory of planned behaviour: The role of questionnaire format and social desirability. Journal of Community and Applied Social Psychology, 9, 261-272.

Baron, R. M., \& Kenny, D. A. (1986). The moderator-mediator variable distinction in social psychological research: Conceptual, strategic, and statistical considerations. Journal of Personality and Social Psychology, 51, 1173-1182.

Bebeau, M. J. (2002). The Defining Issues Test and the Four Component Model: Contributions to professional education. Journal of Moral Education, 31(3), 271-295.

Bebeau, M. J., \& Thoma, S. J. (1999). "Intermediate" concepts and the connection to moral education. Educational Psychological Review, 11(4), 343-360.

Beck, L., \& Ajzen, I. (1991). Predicting dishonest actions using the Theory of Planned Behavior. Journal of Research in Personality, 25(3), 285-301.

Blasi, A. (1984). Moral identity: Its role in moral functioning. In W. Kurtines \& J. Gewirtz (Eds.), Morality, moral behavior and moral development, New York: Wiley.

Bowers, W.J. (1964). Student Dishonesty and its Control in College. New York: Bureau of Applied Social Research, Columbia University.

Carpenter, D.D., Harding, T.S., Finelli, C.J., Montgomery, S.M. \& Passow, H.J. (2006). Engineering Students' Perceptions of and Attitudes Toward Cheating. Journal of Engineering Education, 95(3), 181-194.

Carpenter, D.D., Harding, T.S. \& Finelli, C.J. (2006). The implications of academic dishonesty in undergraduate engineering on professional ethical behavior. Proceedings of the 2006 World Environmental and Water Resources Congress, Omaha, NB. =

Hart, D., Atkins, R. \& Ford, D. (1998). Urban America as a context for the development of moral identity in adolescence. Journal of Social Issues, 54, 513-530.

Etter, B.K., Harding, T.S., Finelli, C.J., \& Carpenter, D.D. (2004). The role of moral philosophy in promoting academic integrity among engineering students. Proceedings of the $34^{\text {th }}$ Frontiers in Education Conference, Savannah, GA. (IEEE Catalog Number 04CH37579C).

Finelli, C.J., Szwalek, J.L., Harding, T.S. \& Carpenter, D.D. (2005). A case study of research in engineering education: Designing, testing, and administering the PACES-2 Survey on academic integrity. Proceedings of the $35^{\text {th }}$ Frontiers in Education Conference, Indianapolis, IN. (IEEE Catalog Number 05CH37667C).

Gibbons, M. (2005a). Databytes: Women in Engineering. PRISM. Washington, D.C.: American Society for Engineering Education. 20-21. October 2005.

Gibbons, M. (2005b). The Year in Numbers. Retrieved on January 17, 2007 form (www.asee.org/publications/profiles/upload/2005ProfileEng.pdf). American Society for Engineering Education. 
Harding, T.S., Finelli, C.J. \& Carpenter, D.D. (2006a). Examining the underlying motivations of engineering undergraduates to behave unethically. Proceedings of the 2006 ASEE National Conference and Exposition, Chicago, IL.

Harding, T.S., Finelli, C.J. \& Carpenter, D.D. (2006b). Cheating in college and its influence on ethical behavior in professional practice. Proceedings of the 2006 ASEE Annual Conference \& Exposition, Chicago, IL.

Harding, T.S., Carpenter, D.D., Finelli, C.J. \& Passow, H.J. (2004a). Does academic dishonesty relate to unethical behavior in professional practice? An exploratory study. Science and Engineering Ethics. 10, 311-324.

Harding, T.S., Carpenter, D.D., Finelli, C.J. \& Passow, H.J. (2004b). The influence of academic dishonesty on ethical decision making in the workplace: A study of engineering students. Proceedings of the ASEE Annual Conference and Exposition, Salt Lake City, UT.

Harding, T.S., Carpenter, D.D., Finelli, C.J. \& Passow, H.J. (2003a). The relationship between academic dishonesty and ethical behavior in engineering practice. Paper presented at the 2003 Ethics and Social Responsibility in Engineering and Technology Conference, New Orleans, LA.

Harding, T.S., Carpenter, D.D., Finelli, C.J. \& Passow, H.J. (2003b). An examination of the relationship between academic dishonesty and professional behavior. Proceedings of the $33^{\text {rd }}$ Annual Frontiers in Education Conference, Boulder, CO. (IEEE Catalog Number: 03CH37487C).

Harp, J., \& Taietz, P. (1966). Academic integrity and social structure: A study of cheating among college students. Social Problems. 13(4), 365-373.

King, P.M. \& Mayhew, M.J. (2002). Moral judgment development in higher education: insights form the Defining Issues Test. Journal of Moral Education. 31(3), 247-270.

Kohlberg, L. (1976). Moral stages and moralization: the cognitive- developmental approach. In Likona, T. (Ed.), Moral development and behavior. New York: Holt, Rinehart, \& Winston.

Kohlberg, L. (1981). The Philosophy of Moral Development (Vol. 1). San Francisco, CA: Harper and Row.

MacKinnon, D. P., Warsi, G., \& Dwyer, J. H. (1995). A simulation study of mediated effect measures. Multivariate Behavioral Research, 30(1), 41-62.

McCabe, D.L. (1997). Classroom cheating among natural science and engineering majors. Science and Engineering Ethics. 3, 433-445.

National Academy of Engineering (2003). Emerging technologies and ethical issues in engineering. Washington, DC: National Academy Press.

National Academy of Engineering (2004). The engineer of 2020: Visions of engineering in the new century. Washington, DC: National Academy Press.

Nonis, S., \& Swift, C.O. (2001). An examination of the relationship between academic dishonesty and workplace dishonesty: A multicampus investigation. Journal of Education for Business. 77(2), 69-77.

Pascarella, E.T. \& Terenzini, P.T. (1991) How College Affects Students: findings and insights from twenty years of research. San Francisco, CA: Jossey-Bass. 
Passow, H.J., Mayhew, M.J., Finelli, C.J., Harding, T.S. \& Carpenter, D.D. (2006). Factors influencing engineering students' decisions to cheat vary by type of assignment. Research in Higher Education. 47(7), 643-684.

Paulhus, D.L. (1991). Measurement and control of response bias. In Robinson, J.P., Shaver, P.R. \& Wrightsman, L.S. (Eds.), Measures of Personality and Social Psychological Attitudes. San Diego, CA: Academic Press, Inc.

Preacher, K. J. \& Leonardelli, G.J. (2004) Calculation for the Sobel test: An interactive calculation tool for mediation tests. Retrieved on July 17th, 2004 from http://www.unc.edu/ preacher/sobel/sobel.htm.

Rest, J.R., \& Narvaez, D. (1994). Moral Development in the Professions: Psychology and Applied Ethics. Hillsdale, NJ: Lawrence Erlbaum Associates.

Rest, J.R., Narvaez, D., Bebeau, M., \& Thoma, S. J. (1999a). Postconventional moral thinking: A neo-Kohlbergian approach. Mahwah, NJ: Lawrence Erlbaum Associates.

Rest, J.R., Narvaez, D., Thoma, S. J., \& Bebeau, M. (1999b). DIT2: Devising and testing a revised instrument of moral judgment. Journal of Educational Psychology, 91(4), 644-659.

Rest, J.R., Thoma, S. J., \& Edwards, L. (1997). Designing and validating a measure of moral judgment: Stage preference and stage consistency approaches. Journal of Educational Psychology, 89(1), 5-28.

Rogers, G. (2002). Rethinking moral growth in college and beyond. Journal of Moral Education. 31(3), 325-338.

Sanders, C.E. (1990) Moral reasoning of male freshmen, Journal of College Student Development, 31, 5-8.

Sims, R.L. (1993). The relationship between academic dishonesty and unethical business practices. Journal of Education for Business. 68(4), 207-211.

St. Pierre, K.E., Nelson, E.S. \& Gabbin, A.L., (1990). A study of ethical development of accounting majors in relation other business and non-business majors, Business and Professional Ethics Journal, 15, 79-84.

Whitley, Jr., B.E. (1998). Factors associated with cheating among college students: A review. Research in Higher Education. 39(3), 235-274.

Whitley, Jr., B.E., \& Keith-Spiegel, P. (2002). Academic Dishonesty: An Educator's Guide. Mahwah, NJ: Lawrence Erlbaum Associates, Inc.

Whitley, Jr., B.E., Nelson, A.B. \& Jones, C.J. (1999). Gender differences in cheating attitudes and classroom cheating behavior: A meta-analysis. Sex Roles. 41(9/10), 657-677. 